\title{
Aerodynamic Analysis of the Elytron 2S Experimental Tiltwing Aircraft Alexander Grima ${ }^{1}$, Colin Theodore ${ }^{2}$, Oliver Garrow ${ }^{3}$, Ben Lawrence ${ }^{4}$, Linnea Persson ${ }^{5}$
}

Affiliation $\left({ }^{1}\right.$ Science and Technology Corporation, ${ }^{2}$ NASA Ames Research Center, ${ }^{3}$ Elytron Aircraft, ${ }^{4}$ San Jose State University, ${ }^{5} \mathrm{KTH}$

Royal Institute of Technology)

\begin{abstract}
The Elytron $2 \mathrm{~S}$ is a prototype aircraft concept to allow VTOL capabilities together with fixed wing aircraft performance. It has a box wing design with a centrally mounted tilt-wing supporting two rotors. This paper explores the aerodynamic characteristics of the aircraft using computational fluid dynamics in hover and low speed forward flight, as well as analyzing the unique control system in place for hover. The results are then used to build an input set for NASA Design and Analysis if Rotorcraft software allowing trim and flight stability and control estimations to be made with SIMPLIFLYD.
\end{abstract}

\section{Introduction}

This paper describes the modeling and analysis of the aerodynamic characteristics of the Elytron $2 \mathrm{~S}$, which is a prototype vehicle for 4 and 10 passenger aircraft [1], using the computational analysis tools AVL [2] and RotCFD [3]. AVL is a command line tool using a vortex lattice solver while RotCFD has a user friendly Graphical User Interface utilizing a Reynolds Averaged Navier-Stokes solver. The objective of the research was to model the vehicle and enable predictions of aerodynamic performance that can be used during the design process to refine the final vehicle design. Using the results from the aerodynamic analysis, an input set was constructed to enable the use of NDARC (NASA Design and Analysis of RotorCraft) [4] to generate a performance/trim model for use in SIMPLI-FLYD [5] to generate a flight dynamics model to assess the stability and control characteristics of the vehicle through the flight envelope. These tools will be discussed in a later section.

The comparison between the AVL and RotCFD results will give an indication as to whether AVL can be used confidently in the early stages of design analysis of tilt-wing aircraft. AVL is a vastly faster analysis code relative to RotCFD; however, it is not able to model rotors and their wakes. As the aircraft uses a unique method for control in hover, a short analysis of this control system will be included. These values will be required in estimating control dynamics in NDARC. The analyses described in this paper were performed in hover and low speed flight as this is an area of initial interest for beginning test flights.

The paper first introduces the aircraft and software which go into the analysis, beginning with AVL and continuing into RotCFD to perform a comparison. With this analysis completed, the aircraft was analyzed in forward flight out of ground effect and including rotor interactions with an analysis of elevator authority and pitching moment characteristics, particularly with respect to center of gravity location. Having concluded the forward flight analysis, the aircraft was simulated in hover out of ground effect (OGE). This is followed by an analysis of the control surfaces in hover and estimating the amount of control forces and moments they will generate. Finally, the results were summarized and conclusions drawn.

\section{The Experimental Aircraft}

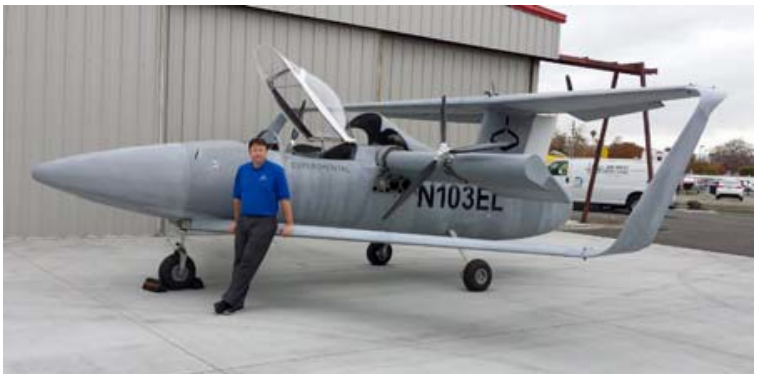

Figure 1: Picture of the Elytron 2S experimental aircraft.

The Elytron 2S, seen in Figure 1, is a single-seat proof-of-concept experimental prototype of the 4 and 10 passenger aircraft designs developed by Elytron [1]. These 4 and 10 passenger aircraft are envisaged for use as an air taxi and for transportation of crews to oil and gas rigs. This advanced VTOL design consists of a box wind and a small, centrally mounted tilt-wing with rotors. This aircraft utilizes a unique control system in hover; the design deflects the rotor wake with louvers, in comparison to conventional helicopter controls, i.e. swashplate, collective, and cyclic. As shown in blue in Figure 2, these louvers would be centrally mounted under the rotors to allow control of rate of climb, roll, and yaw. Under this design, pitch control would be achieved using a rear mounted air blowing system.

Figure 2: Control surfaces on the Elytron 2S, blue representing hover control and red forward flight. 
The $2 \mathrm{~S}$ proof of concept aircraft, as shown in Figure 1, weighs less than 2,000lbs, and is intended to test the forward flight characteristics of this box wing concept. This test aircraft uses off-the-shelf propellers that are fixed pitch and thrust is controlled by changing propeller speed. Both propellers are driven at the same speed by a single engine. The production aircraft is envisioned to have collective pitch on the propellers that would then operate at constant speed. Since the test aircraft is not intended to operate in hover, it does not include the rear mounted air blowing system, and does not have an operating louver system.

\section{$A \boldsymbol{V L}$}

The Athena Vortex Lattice (AVL) tool is used for the initial characterization of the aerodynamic of the experimental vehicle. This software uses an extended vortex lattice model for lifting surfaces and a slender-body model for fuselages and nacelles. This makes it suitable for analysis of rigid aircraft of an arbitrary configuration [2]. With AVL it is possible to make estimations of aerodynamic characteristics of each lifting surface individually, something that is required to build the NDARC input set.

\section{$\operatorname{RotCFD}$}

RotorcraftCFD (RotCFD) is a recently developed mid-fidelity CFD tool designed specifically for rotorcraft analysis [7] [8]. It is possible to model rotors both with an actuator disk model and with a blade element model. This is done with two-dimensional airfoil data allowing for relatively fast computations in unsteady cases. Recently, RotCFD has been released in a parallelized version allowing for even faster analysis of rotorcraft. This software has been used extensively within NASA Ames Research Center's Aeromechanics Branch to analyze rotor models [9] as well as wind tunnel result validation [10] and prediction [6].

RotCFD is built on multiple modules, allowing diversity in analysis problems. For the analyses performed in this paper, RotUNS is utilized. This module is an unstructured flow solver capable of performing rotor-body interaction simulations, among others. RotUNS's governing equations are unsteady, incompressible Reynolds Averaged Navier-Stokes equations using a k-E turbulence model. This solver utilizes a Cartesian unstructured grid in the far field together with a body-fitted tetrahedral grid near the body.

As the design of the rotors for the concept aircraft are not yet completed, the RotCFD analysis uses rotor models developed for the XV-15 [6] that have been scaled for this aircraft. Scaled XV-15 rotors are used as the propellers used on the $2 \mathrm{~S}$ aircraft are not appropriate for generating lift in hover.

RotUNS models the rotor as a distribution of momentum sources This allows the rotor to be fitted with a Cartesian grid instead of requiring a body fitted grid. The momentum imparted by the rotor is dependent on geometry and flow characteristics of the rotor. These characteristics are defined in part through C81 database files, describing the 2D cross-sectional airfoil performance data, at radial positions together with chord and twist curves along the radius of the blade. Cyclic and flapping can also be included in the model, while the radius, number of blades, cone angle, cutout radius, and hinge offset affect the geometry. Finally, setting collective pitch and tip speed culminates in a full rotor model. The rotor can be modeled both as steady and unsteady; the steady case treating the rotor as a time-

Page 2 of 15 averaged source of momentum without taking into account instantaneous blade position.

\section{$N D A R C$}

NASA Design and Analysis of Rotorcraft (NDARC) [11] [12] is an aircraft system analysis tool designed for conceptual design and technology impact assessments. Written for versatility and concept development, the software is able to quickly model advanced rotorcraft systems and analyze mission performance using models typically appropriate for the conceptual design environment.

An NDARC job consists of one or more cases able to perform design or analysis tasks. A design task involves sizing of an aircraft to meet mission requirements while an analysis task can involve off-mission design performance, flight performance analysis, and general component performance mapping. For analysis tasks, the design can come from a sizing task, from a previous NDARC job, or an independent design database. The culmination of this paper is an aircraft NDARC input set where the geometry and aerodynamics stem from the analysis performed. The performance models for the rotors and propulsion system are taken from an existing XV-15 model.

The aircraft consists of a set of components, including rotors, wings, tail surfaces, and propulsion. For each component a set of attributes exist; performance, drag, weight, and geometry. Each of these attributes can be calculated or defined. Using different configurations of these basic components, a variety of designs can be generated and analyzed.

\section{Analysis and Results}

\section{$A \boldsymbol{V L}$}

The model used for the AVL model is taken from an OpenVSP [13] model provided by Elytron. Figure 3 shows the representation of this model, which is converted into lifting surfaces for AVL as shown in Figure 4. The airfoil cross-sections for each wing are extracted from the OpenVSP model.

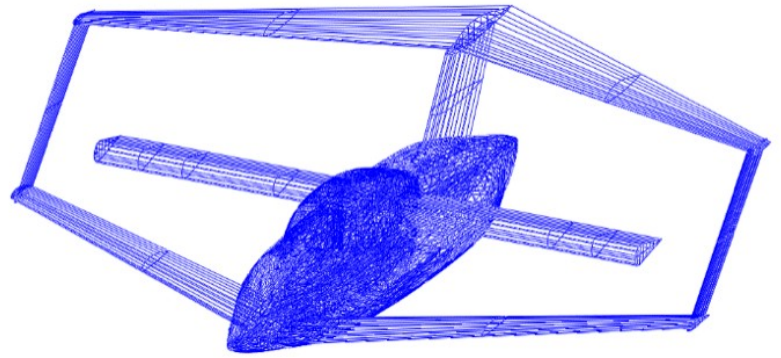

Figure 3: OpenVSP model of the Elytron 2S.

The analysis in AVL is performed without the fuselage in order to capture the wing characteristics. Lift and drag curves are required by NDARC; therefore, a sweep of angle of attack was performed. To get high resolution many cases are run. To simplify this, a script was used to automatically generate cases and a batch script to run them all while saving AVLs output data. AVL does not account for parasitic 
drag, only induced, therefore the airfoils are analyzed in XFOIL [14] for an estimate of zero-lift drag. XFOIL uses the same airfoil data as AVL and therefore the same airfoils can be easily used.

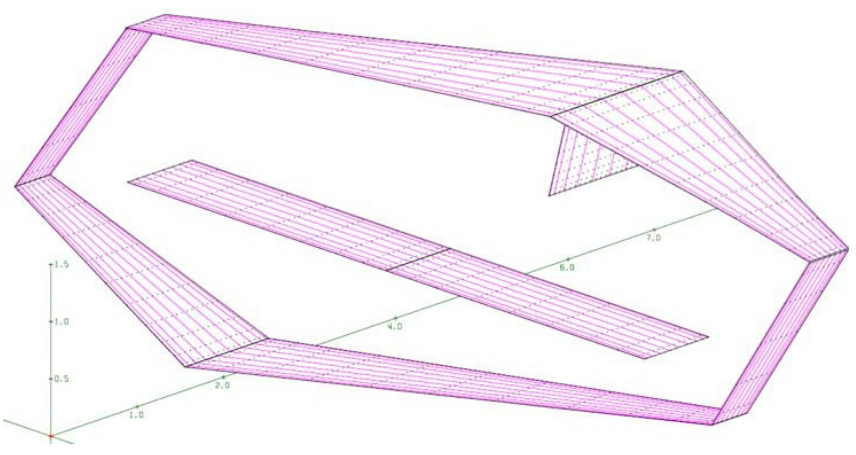

Figure 4. AVL model used for analysis.

The fuselage drag was not modeled in AVL. In order to account for the fuselage drag, the zero-lift drag parasite drag was estimated with Hoerner's [15] streamlined body with a canopy. The component buildup of the $\mathrm{C}_{\mathrm{D} 0}$ is presented in Table 1 .

Table 1: Zero-lift drag breakdown using Hoerner's streamlined body for the fuselage and XFOIL for the lifting surfaces.

\begin{tabular}{|l|l|}
\hline Wing & $\mathrm{C}_{\mathrm{D} 0}$ \\
\hline Forward wing & 0.0004 \\
\hline Center wing & 0.0005 \\
\hline Aft wing & 0.0003 \\
\hline Vertical stabilizer & 0.0003 \\
\hline Vertical wings & 0.0003 \\
\hline Fuselage & 0.0503 \\
\hline Total zero lift drag & 0.0577 \\
\hline
\end{tabular}

The results from this analysis will be compared with the results from RotCFD in the coming section.

\section{$\operatorname{RotCFD}$}

The geometry model used in the RotCFD analysis differs slightly from that used in the AVL analysis. Instead of the OpenVSP model, a CAD model of the actual prototype is provided that is converted into a water-tight stereo lithography model. This model is split into its different parts: forward wing, aft wing, center wing, vertical wings and stabilizer, and fuselage to allow a breakdown of force and moment contributions between the different aerodynamic surfaces. The analysis begins with the bare airframe for comparison to the results from AVL, then includes the rotors in forward flight.

\section{Bare airframe (no rotors) analysis for AVL comparison}

The model used in RotCFD, shown in Figure 5, differs slightly from that used in AVL. It is taken from the CAD geometry of the $2 \mathrm{~S}$

Page 3 of 15 prototype. It gives a better transition between horizontal and vertical wing sections as well as a slightly different center line configuration for fore and aft wings.



Figure 5. Model used in RotCFD to make comparisons with AVL data.

The RotCFD comparison was performed with and without the fuselage at different angles of attack with the results presented in Figures 6-9. These results are calculated at a $57 \mathrm{kts}$ free stream velocity at sea level.

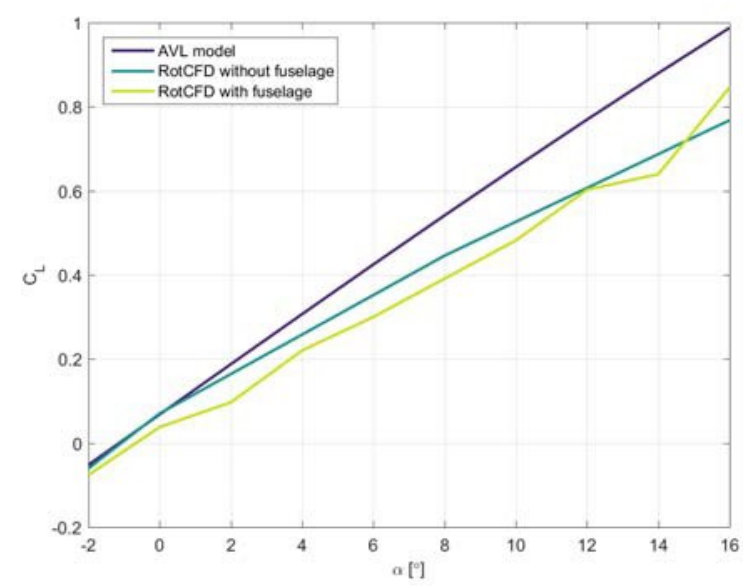

Figure 6: Comparison of lift coefficients from AVL and RotCFD analysis at $57 \mathrm{kts}$ without rotors.

Figure 7: Comparison between AVL and RotCFD drag coefficients at $57 \mathrm{kts}$ without rotors. 


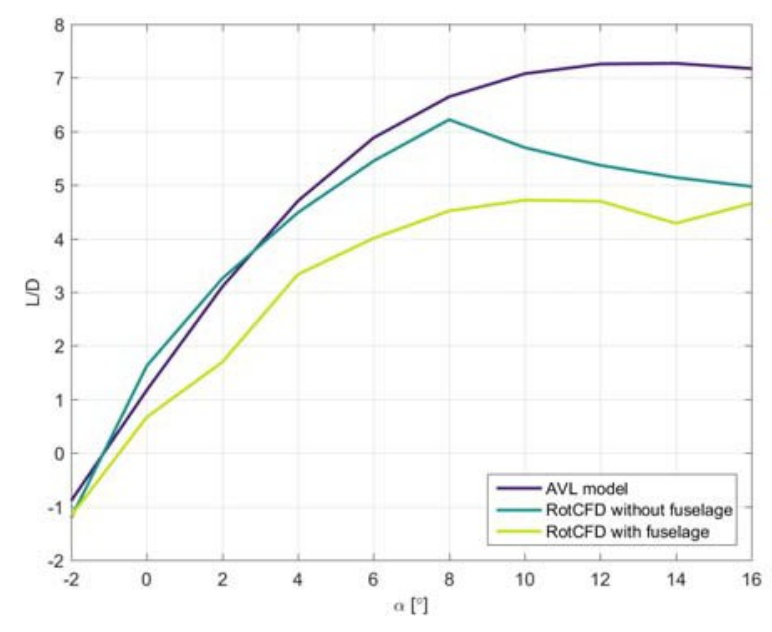

Figure 8: Comparison between lift over drag values for AVL and RotCFD analysis at $57 \mathrm{kts}$ without rotors.

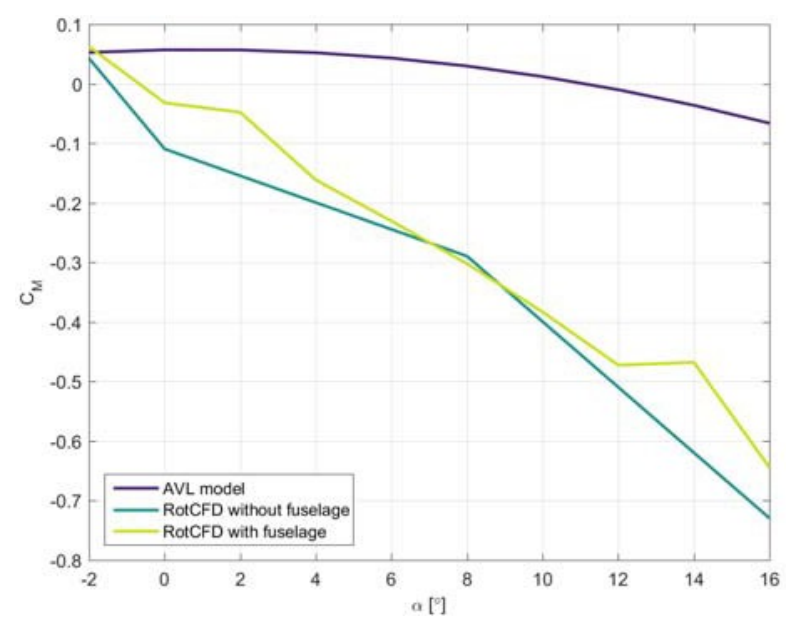

Figure 9: Comparison between AVL and RotCFD pitching moment coefficients at $57 \mathrm{kts}$ without rotrs.

For small angles of attack, the lift values correspond well between AVL and RotCFD; however, as the angle of attack increases, the AVL analysis predicts a higher lift than RotCFD. Due to the fidelity of the RotCFD grid, it is possible that RotCFD is underestimating the generated lift as airfoil trailing edges are difficult to capture smoothly. The drag from the AVL analysis only changes with induced drag and does not capture the change in profile drag with change in angle of attack. However, as with most CFD codes, RotCFD may be limited in its drag modeling so these drag values must be taken as a rough estimate. The drag and lift differences between AVL and RotCFD compound in the lift over drag ratio to create quite large differences in predicted values. It seems reasonable to estimate a value around 4 as the L/D max.

The $\mathrm{L} / \mathrm{D}$ is calculated at a velocity at $57 \mathrm{kts}$, however both AVL and RotCFD currently assume incompressibility. For analysis at higher velocities, it is possible that different analysis tools would be required if compressibility has a significant influence on aerodynamics.
The reason for the large difference in pitching moment is unknown; however, both analyses indicate a statically stable configuration. It should be remembered that this comparison is for the airframe without rotors and therefore, does not contain rotor wake interaction and so only the glide stability without rotors is attained. The next section includes rotor modeling and the effects the rotor wake may have on the lift and pitch aerodynamics.

From this analysis it is concluded that for lift and drag property estimations, AVL is adequate for a first pass. However for more refined analysis, higher fidelity codes are required. It should be noted that the time it takes to run one case in AVL is a few seconds, whereas each case in RotCFD take between 1-2 days for this configuration on a GPU accelerated desktop.

\section{Rotor wake interaction}

In the following analysis, rotors are used to estimate flow interactions between rotor wake and wings. As the proposed rotors do not have a final design, a scaled XV-15 rotor model was used. The XV-15 is a tilt-rotor aircraft developed by Bell, in conjunction with NASA and the Army, in the 1970's. Its rotors are designed with a compromise between hover performance and forward flight efficiency. Due to this rotor having been used and its data available through analysis already performed [6] at the Aeromechanics Branch at NASA Ames

Research Center, it is chosen as a good temporary model. As the XV15 rotor was larger than the proposed rotor, the model is scaled down to the proposed size. The rotor is also modeled as a five bladed rotor instead of three since the initial concept vehicle was envisaged to have five bladed propellers. With the rotor scaled down, the RPM is increased to reach a similar tip speed. A brief analysis was then performed with the rotor in RotCFD to estimate a required collective pitch to achieve the design thrust of $1000 \mathrm{lbs}$ per rotor.

Forward flight was analyzed to include the rotors and the model is presented in Figure 10 together with a grid slice. The moments include the forces from the rotors and were taken about a reference point that was chosen to be $2 \mathrm{ft}$ below and ahead of the center wings rotational axis. This was a rough estimate of c.g. location. These values were then used in a pitch stability estimation where the c.g. location was varied. An analysis of control authority and turbulent interactions and wake effects on the aft wing and elevators could not be accurately estimated in the time frame; therefore, only a short analysis is included after the stability analysis.

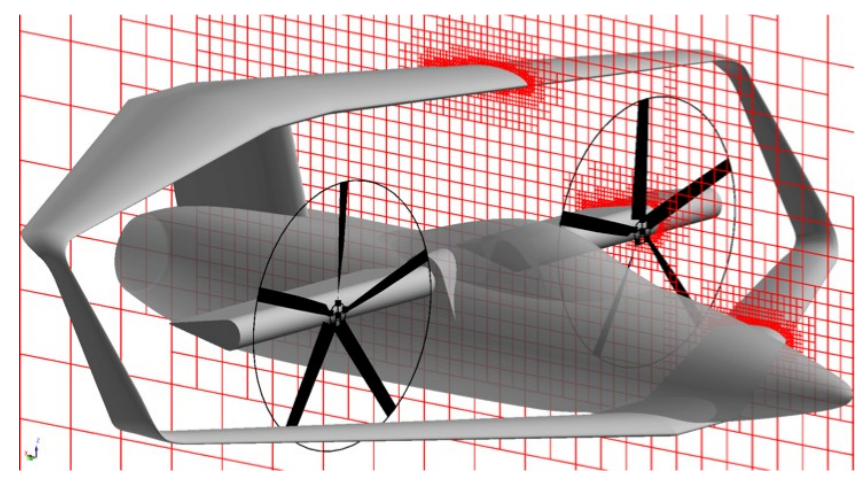

Figure 10. Forward flight model used in RotCFD. 


\section{Force and moment estimations from RotCFD}

The analysis for forward flight was performed at $35 \mathrm{kts}, 57 \mathrm{kts}$, and $70 \mathrm{kts}$. As this aircraft is a tilt-wing, these analyses were performed for not only a range of angle of attack but also different tilt angles of the center wing.

Figures 12-13 present the results of these analyses while Figure 11 shows the flow interaction estimation made with RotCFD for the case with rotors at $57 \mathrm{kts}$ and zero tilt of the center wing. From this visualization, it is clear that the rotor wake is causing a higher velocity flow on the lower side of the aft wing than on the top at low airframe speeds, thus causing a negative lift and a resulting nose-up pitching moment.

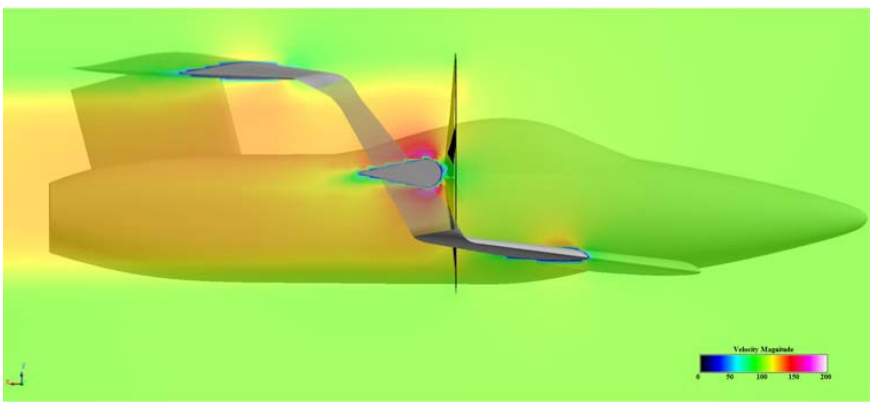

Figure 11: Rotor flow interaction with aft wing at $57 \mathrm{kts}, 0^{\circ}$ angle of attack and $0^{\circ}$ center wing tilt.

As previously mentioned the results presented in Figures 12-13 do not include contributions from the rotors. Figure 14 shows how the pitching moment varies with angle of attack and velocity for a center wing tilt of $16^{\circ}$ including the contributions from the rotors.
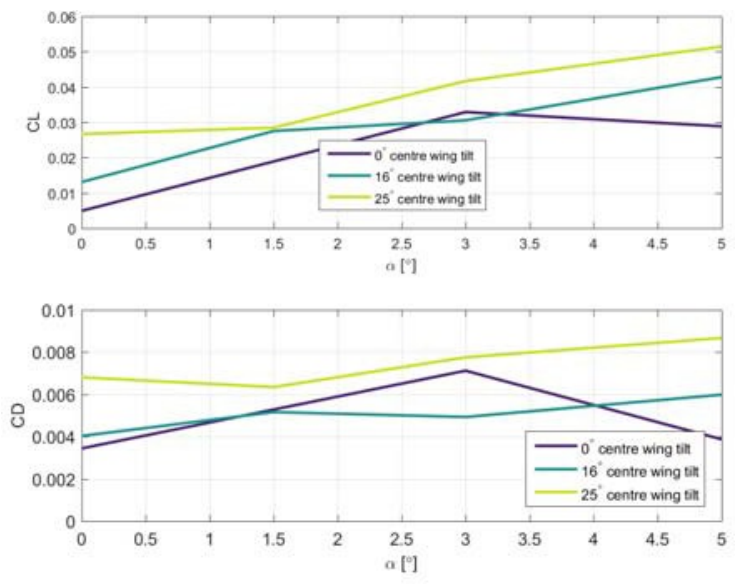

Figure 12: Lift and drag estimations at $57 \mathrm{kts}$ including rotors.

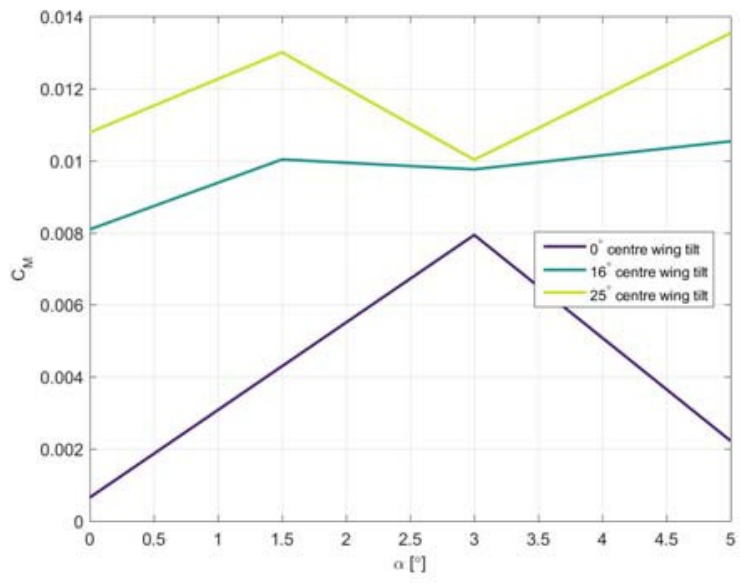

Figure 13: Pitching moment estimation at $57 \mathrm{kts}$ including rotors.

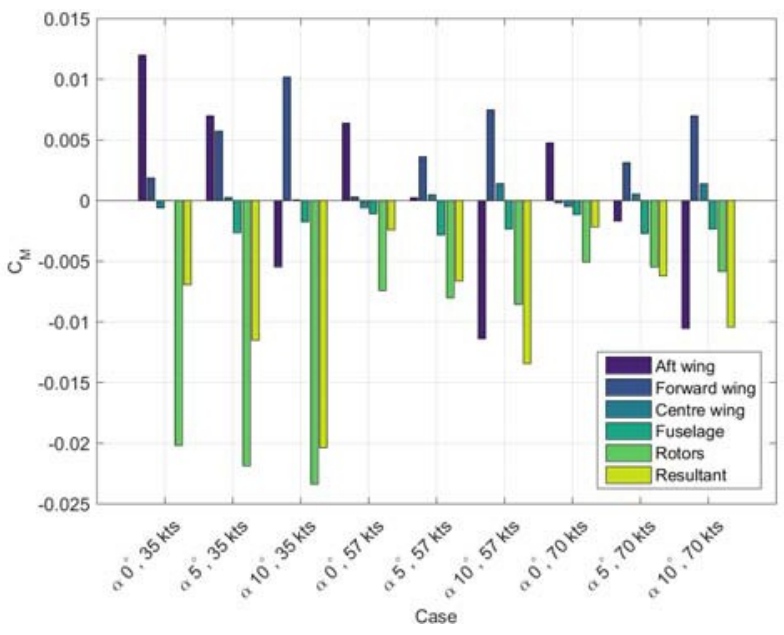

Figure 14: Pitching moment varying with alpha and free-stream velocity including rotor interactions with a $16^{\circ}$ center wing tilt.

In these cases, the moment is again taken $2 \mathrm{ft}$ below and ahead of the center wing's rotational axis. Figure 14 shows that for each case considered the resulting moment is nose down; however, the nosedown pitching moment does decrease in magnitude as the speed increases. Focusing on the contribution of the aft wing, it is also evident that with increased velocity, the magnitude of the nose-up pitching moment reduces. This is thought to be due to a decrease in the adverse velocity delta over the aft wing due to the rotor wake. However, due to an increase in lift from the forward wing, the total pitching moment would seem to become more positive with increased velocity. These results indicate that if the center of gravity was placed at the point $2 \mathrm{ft}$ below and ahead for the center wing rotational axis, then the resulting pitching moment on the aircraft would be nose down, which is the desired condition for stability. Due to the wake propagating below the aft wing, deflecting the elevators for negative pitch would place them in the flow of the rotor and possibly allow for sufficient control authority to be available to keep the nose down through this region. This is analyzed further in a coming section.

Page 5 of 15 


\section{Pitch stability}

In this part of the analysis, the center of gravity is assumed to be $2 \mathrm{ft}$ below and ahead of the center wing. This location was then varied in the stream wise direction to estimate the pitching moment's sensitivity to movement of the center of gravity; Figure 15 presents the range of locations used in this analysis in red.

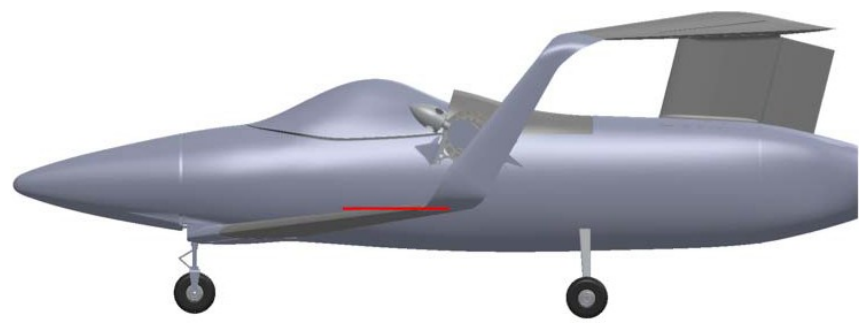

Figure 15: Variation of c.g. location.

This analysis does not include control surfaces so these results are not for a trimmed state, yet a picture of the behavior of the aircraft can still be predicted. Figure 16 shows an example pitching moment contribution breakdown around a c.g. located $2 \mathrm{ft}$ below and ahead of the center wing's rotational axis for a number of center wing tilt cases.



Figure 16: Breakdown of pitching moment for certain angles of attack and center-wing tilt configurations at $57 \mathrm{kts}$.

It appears that as the angle of the tilt wing increases, the aft wing perturbs the aircraft's pitching moment. This was probably due to the rotor wake interaction, and Figure 17 would suggest placing the c.g. forward of the center wing keeps pitching moment negative for all analyzed cases.

As the center of gravity is moved aft towards the center wing, the pitching moment becomes smaller until it eventually becomes noseup. The most aft location that the c.g. could be placed while still maintaining a negative pitching moment is about $1.5 \mathrm{ft}$ forward of the center wing rotational axis. It should also be noted that these results are in steady state, not a dynamic situation as would be encountered during a transition.
The combination of angle of attack and center wing tilt angle should be analyzed further to ensure sufficient lift is available while maintaining a negative pitching moment for stability. This initial analysis also indicates that the flight conversion window for this vehicle from hover to forward flight will need to be chosen carefully.

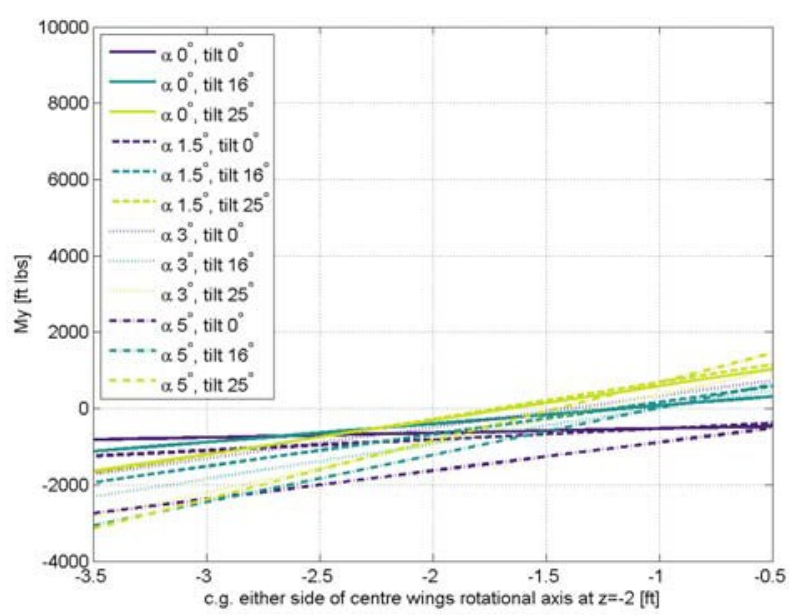

Figure 17: Pitching moment variation with c.g. location for a variety of configurations and flight conditions.

\section{Elevator authority}

A simple analysis of the elevator authority was performed in two cases. The cases were at a $5^{\circ}$ angle of attack and a center wing tilt of $16^{\circ}$ at $35 \mathrm{kts}$ and $57 \mathrm{kts}$. The elevators on the aft wing were deflected $35^{\circ}$ in an attempt to create a nose down pitching moment. It is suspected that by deflecting the high velocity flow down, the adverse interactions may be mitigated. Transient effects were not modeled and the results were simply that of a steady forward flight case and the pitching moment presented in Figure 18.

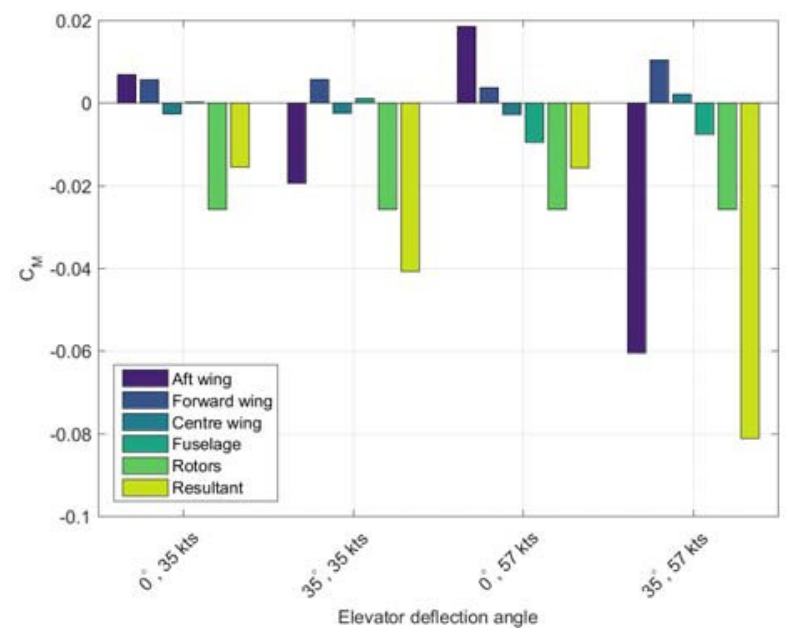

Figure 18: Pitching moment breakdown comparing two cases with different elevator deflection at $5^{\circ}$ angle of attack and $16^{\circ}$ center wing tilt at $35 \mathrm{kts}$ and $57 \mathrm{kts}$. 
Comparing the results between deflected and undeflected elevator in Figure 18 highlights the contribution of pitching moment from the aft wing. Extensive modeling of control surfaces has not been performed in RotCFD so it is unclear as to how representative this result is to the actual control authority; however, the elevator behavior seems to operate as expected. From these results it can be concluded that pitch control can be achieved using elevator deflections but further analysis would be required to fully characterized to control authority of the elevator. A result of this analysis in low speed forward flight, where the pitching moment is nose-down in all cases, would indicate that a nose-up moment due to elevator deflections or rear blowing mechanism would be needed to trim the aircraft. If the air blowing mechanism is placed in the tail a negative lift is required to generate the nose-up pitching moment. A better design choice would be to install a lift fan in the nose, which would augment the lift from the rotors and wings, as well as generating the nose-up pitching moment needed to trim the aircraft. A further benefit of setting the center of gravity so that the pitching moment from the aerodynamics of the body are nose down in every case, is that the nose mounted lift fan would only need to generate positive lift to trim the aircraft.

\section{Hover}

Hover was analyzed out of ground effect as this was expected to require the most power. First the airframe was analyzed with the rotor wake interactions. Results from the aerodynamic analysis were then used in a sensitivity analysis to changes in the center of gravity location. Figure 19 presents the model together with the grid used for RotCFD analysis.

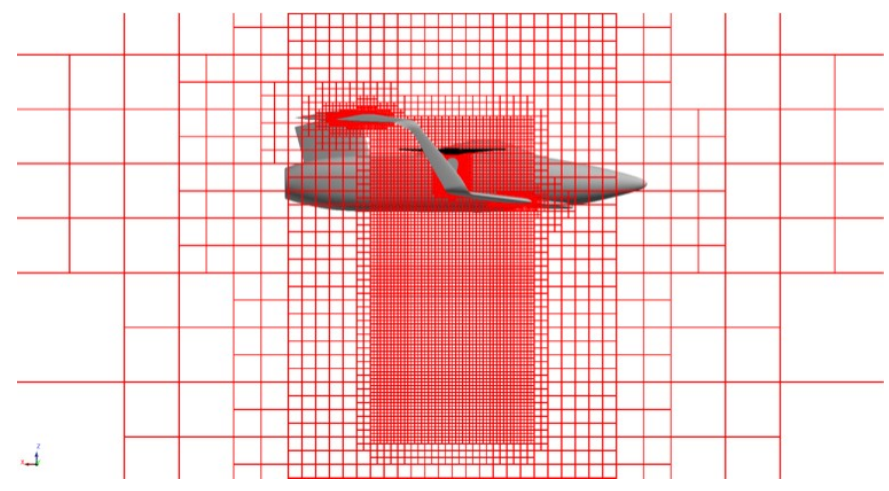

Figure 19. Model used for hover analysis.

\section{Aerodynamic analysis}

The aircraft was analyzed in a horizontal position with vertical center-wing and rotor configuration. Due to the proximity of the rotors to the fore and aft wings, large amounts of aerodynamic interaction and high downloads on the wings may be experienced. It is therefore important to analyze the aircraft in hover to understand the effects of these interactions.

The simulation was run until the wake propagated well past the body, giving steady values in force and moment calculations. Figure 20 shows the flow solution of the rotor wake interactions with the body and clearly indicates an interaction between the rotor wake and the forward wing.

Page 7 of 15

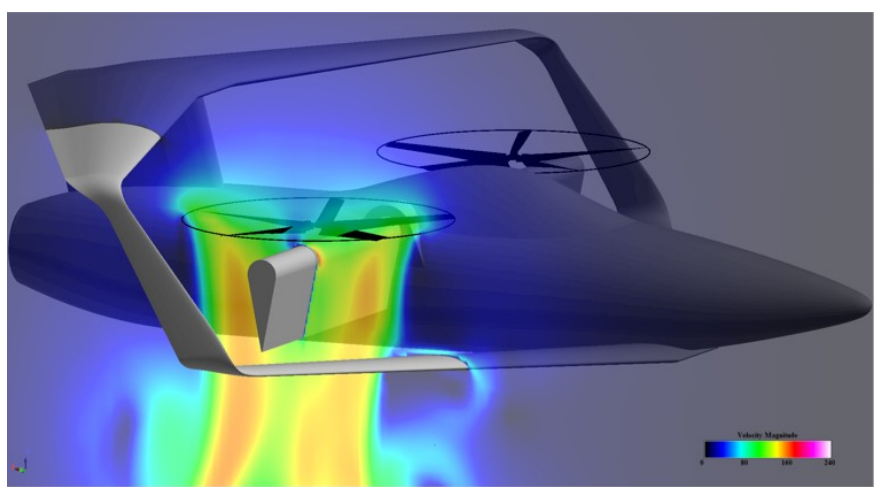

Figure 20. Rotor wake interaction with wings in the rotor shaft plane in hover.

Figures 21-22 show the force and pitching moment on each of the main wing and fuselage surfaces due to the rotor wake interaction.

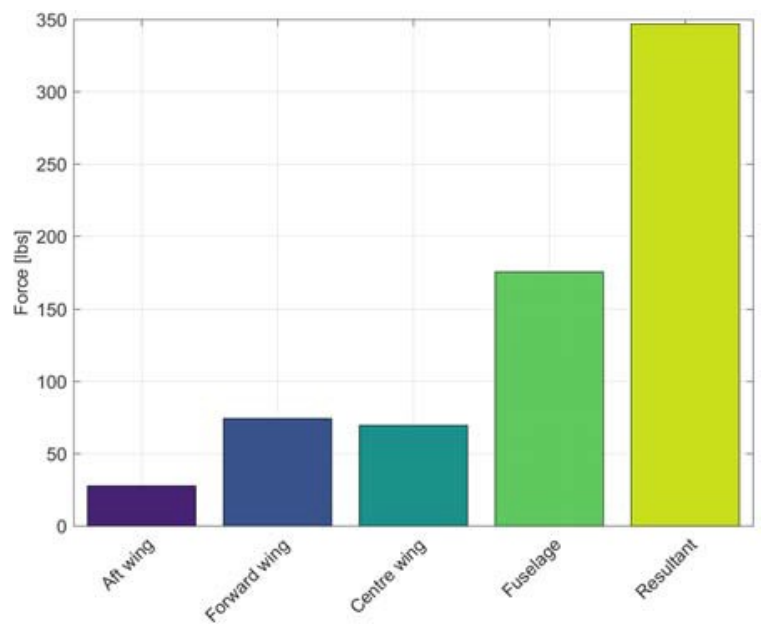

Figure 21: Download breakdown in hover.

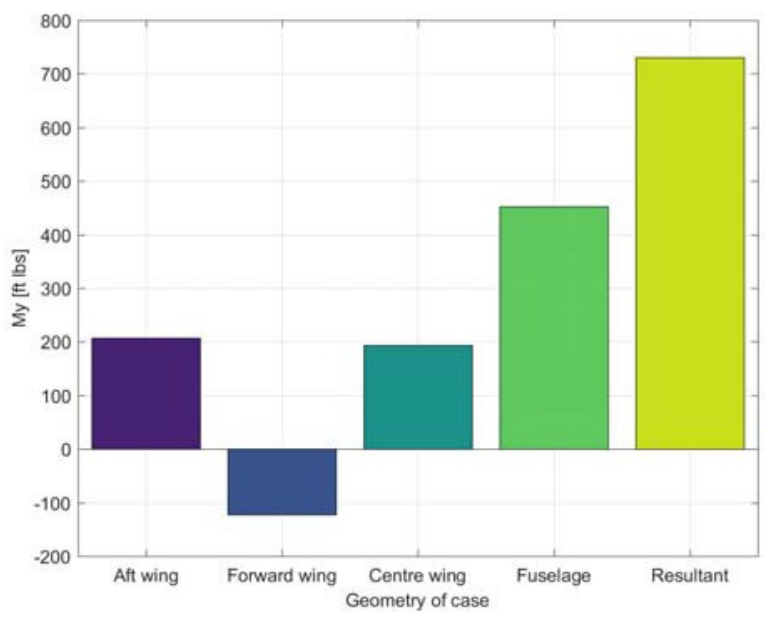

Figure 22: Pitching moment breakdown in hover.

The resulting download is in the expected range, about $350 \mathrm{lbs}$, about $15 \%$ of the total weight of the aircraft. The aerodynamic interaction also produces a nose-up pitching moment. However, the rotor contribution to pitching moment (not included in Figure 22) is of the 
order of $4600 \mathrm{ft}$. lb with the rotors generating $2300 \mathrm{lb}$ of thrust at a location $2 \mathrm{ft}$ aft of the center of gravity. This resultant nose-down pitching moment, with the effect of the rotors included, would ultimately be balanced by a lift fan mounted in the nose of the vehicle. Using the geometry of the $2 \mathrm{~S}$ experimental vehicle, the lift fan would be about $8 \mathrm{ft}$ in front of the center of gravity, requiring a lift fan generating about $600 \mathrm{lb}$ of lift to balance the moment.

Power required to maintain hover out of ground effect can also be estimated through RotCFD. From the above analysis, it is estimated that a torque of $588 \mathrm{ft}-\mathrm{lbs}$ will be required to generate the desired thrust using these rotors. With no losses in the system, a total of $222 \mathrm{hp}$ is estimated to be required per rotor to maintain hover out of ground effect in standard atmosphere; resulting in a required power output by the engine of at least $450 \mathrm{hp}$.

\section{Louvers}

The louver analysis is performed in hover out of ground effect for four cases: ascent, descent, roll, and yaw. As the aircraft does not have a conventional helicopter control system these louvers will be responsible for control in hover. The download was compared between the ascent and descent configurations, while the moments were analyzed for the remaining two cases. Figure 23 shows the four models used; the top models are ascent (a) and descent (b) respectively, while the lower models are roll (c) and yaw (d) respectively.
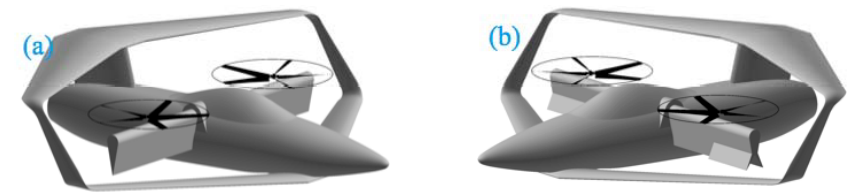

(c)

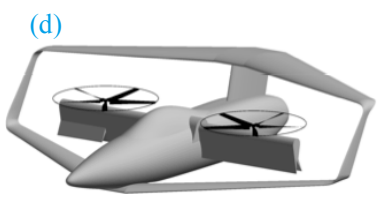

Figure 23: Louver models used in the louver analysis.

\section{Ascent}

The ascent case was set up in the same manner as the previously covered hover case. The same model was used and therefore the forces and moments that arise are the same. The results of this case are used as the baseline for estimating the change in forces and moments due to louver deflection. Figure 24 presents the flow interaction around the undeflected louver.

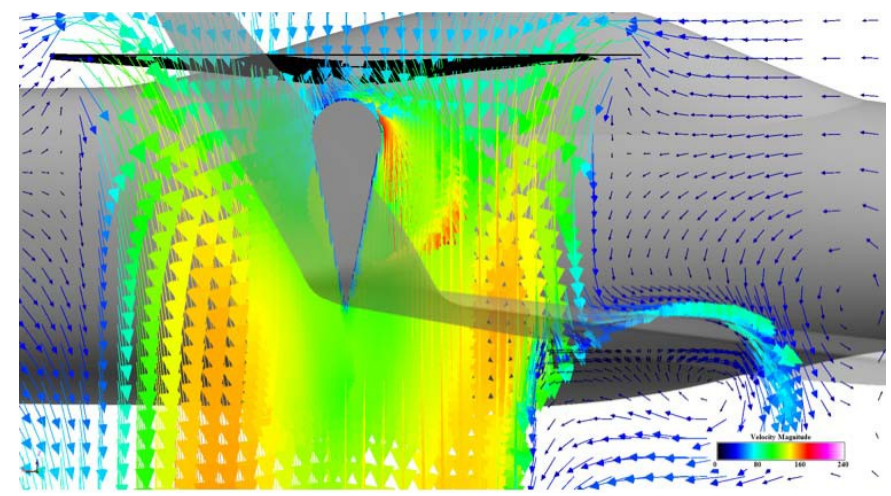

Figure 24: Flow around the undeflected louver in hover.

\section{Descent}

In descent the louvers are deflected symmetrically to their design maximum of $35^{\circ}$. The aim of this configuration is to give a large difference in download which enables control of vertical lift without the use of collective pitch. Due to the symmetrical deflection of port and starboard louvers, no yaw or rolling moment was experienced. The flow experienced below the rotor on the deflected louver is shown in Figure 25. Comparing this with the undeflected flow in Figure 24, it is apparent that additional flow is being deflected over the forward wing, which increases the download and creates a more nose-down pitching moment, though the impact is small. The results are presented together with the other cases in Figures 28-31 for comparison, and these figures are discussed later in the paper.

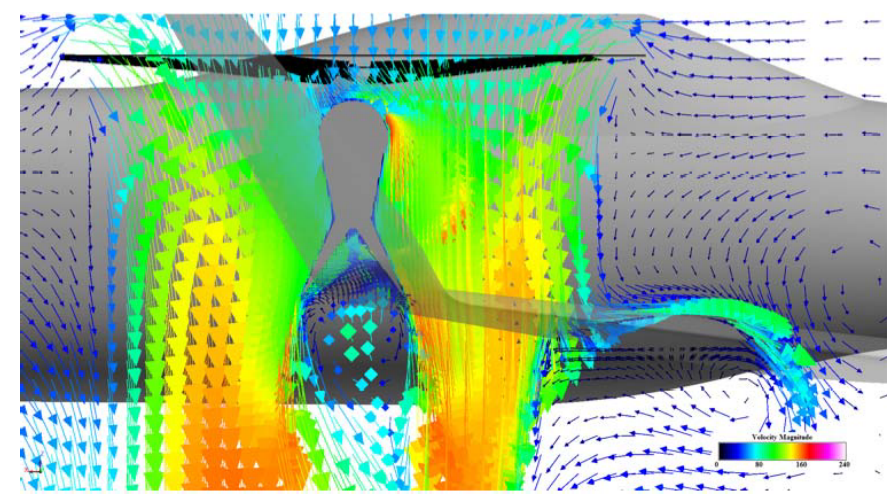

Figure 25. Louver configuration for descent control in hover.

\section{Roll}

To roll the aircraft, one pair of louvers are deflected fully while the pair on the opposite side remain undeflected; this difference in download creates a rolling moment. The flow forward of the center wing is shown in Figure 26. This figure indicates that the flow is inhibited on the deflected side whilst the undeflected side passes freely. 


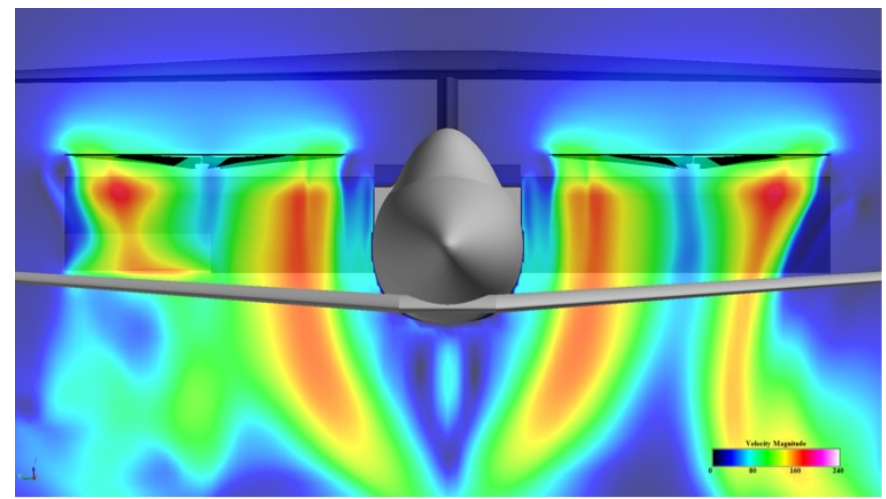

Figure 26. Louver configuration for positive roll in hover.

Due to the asymmetry of the system, a small yawing moment is also generated. These moments are shown in Figures 28-31.

\section{Yaw}

Similar to the roll case, an asymmetrical louver deflection is used to generate opposing forces on the center wing on opposing sides of the aircraft. Figure 27 shows this flow deflection used to generate a negative yaw of the aircraft.

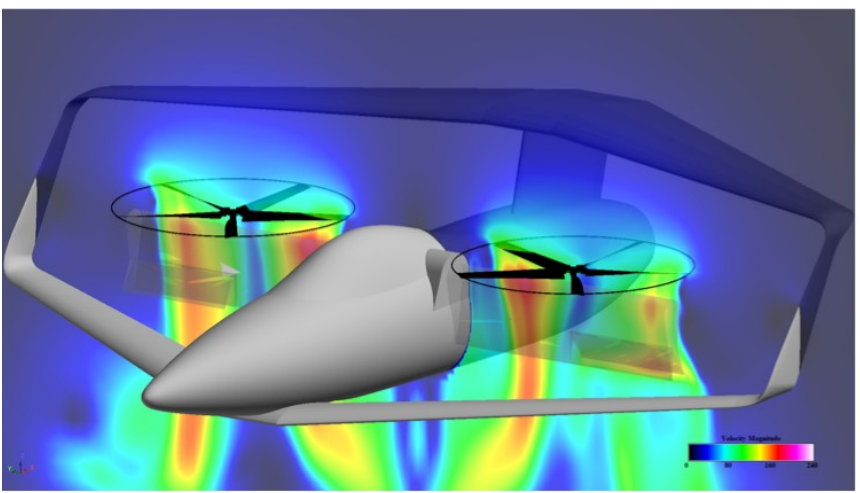

Figure 27. Louver configuration for negative yaw in hover.

Again, due to the dissymmetry of the system, a small rolling moment is also generated. As the rotors are spinning in opposite directions, one louver will experience an approaching rotors downwash while the other a retreating. This is likely a contributing factor to this asymmetry together with the differences in interaction with the forward wing. Again, the results are available in Figures 28-31 to compare with the roll case.

\section{Results of louver analysis}

The forces and moments resulting from the louver analysis are compiled here. Results are split into contributions from each component except the vertical surfaces since their contributions were close to zero for all cases and were therefore omitted. Figure 28 presents lift and drag while the remaining plots, Figures 29-31, present the resulting moments in a point $2 \mathrm{ft}$ below and ahead of the rotational axis of the center wing. Again, the rotors are not included in these results. They have a large contribution to the pitching moment, but as the louvers are not used to control pitch it is omitted to highlight the impact of the body aerodynamics.

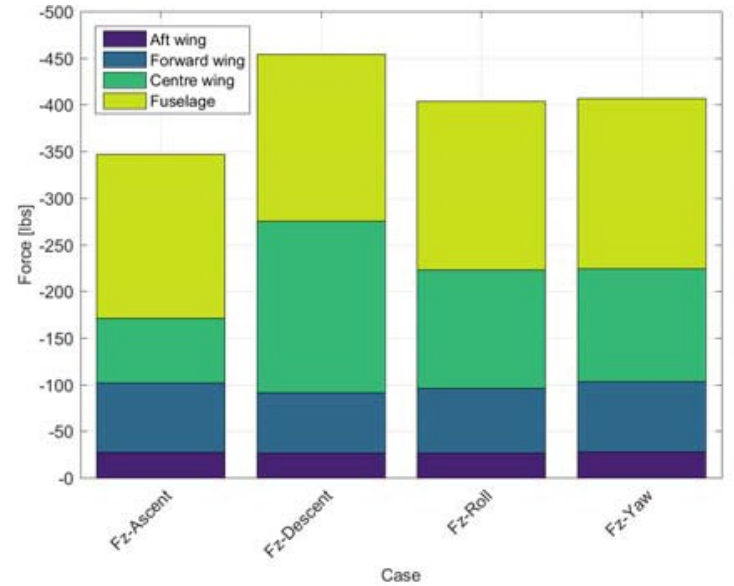

Figure 28: Download force breakdown for different louver cases in hover.

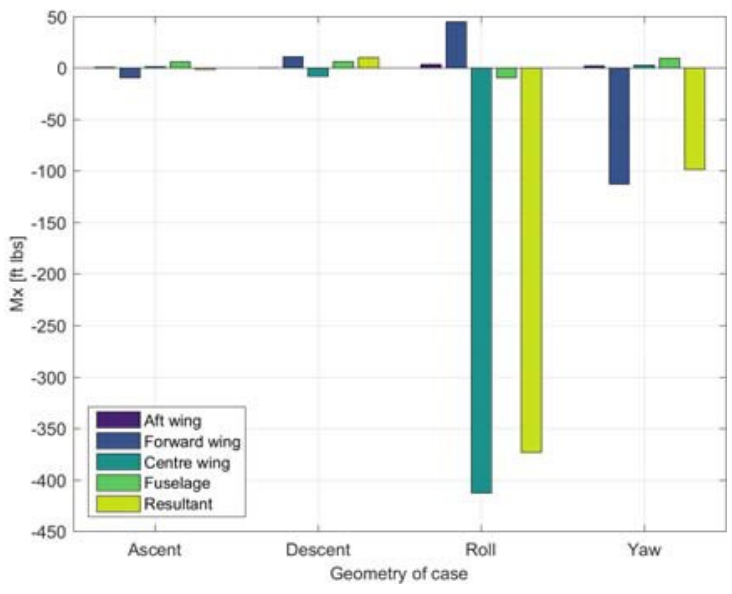

Figure 29: Roll moment breakdown for louver cases in hover.

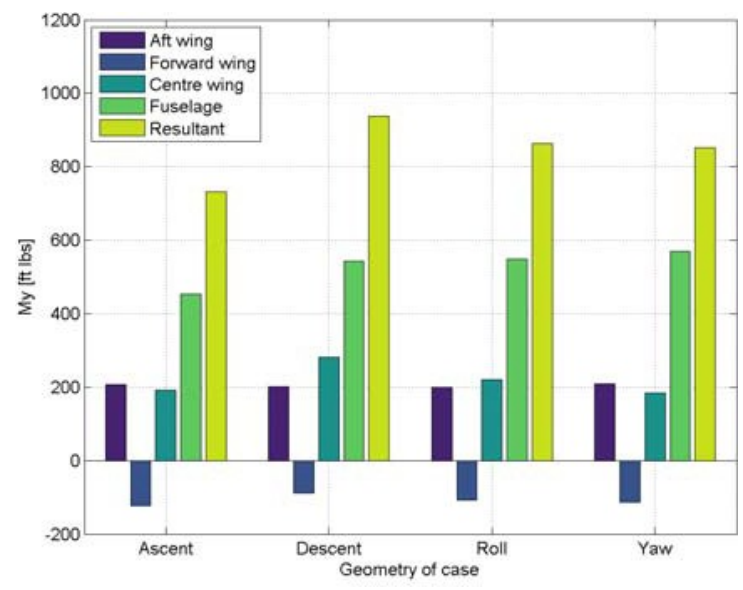

Figure 30: Pitching moment breakdown for the louver cases in hover.

Page 9 of 15 


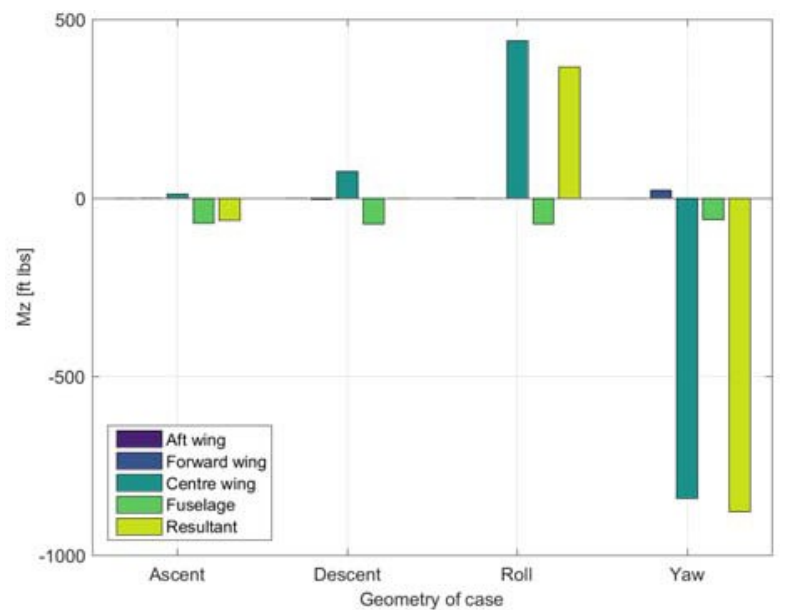

Figure 31: Yaw moment for the analyzed louver cases in hover.

In all cases the pitching moment is small enough that it is expected to be controllable with a forward mounted lift fan. The roll and yaw control do couple with each other but it may be possible to couple the controls in such a way as to have roll and yaw controlled independently. An analysis to ascertain moments generated due to deflection of louver surfaces is required to include coupled deflection. From this it should be possible to generate a coupled control map to isolate roll and yaw moments.

One option for isolating roll through control coupling is proposed here as a simple proof of concept. One louver pair is fully deflected to $35^{\circ}$ for roll while the opposing side, only one louver surface is deflected to $20^{\circ}$ to attempt to counteract the adverse yaw. The results of this coupling are presented in Figures 32-33.

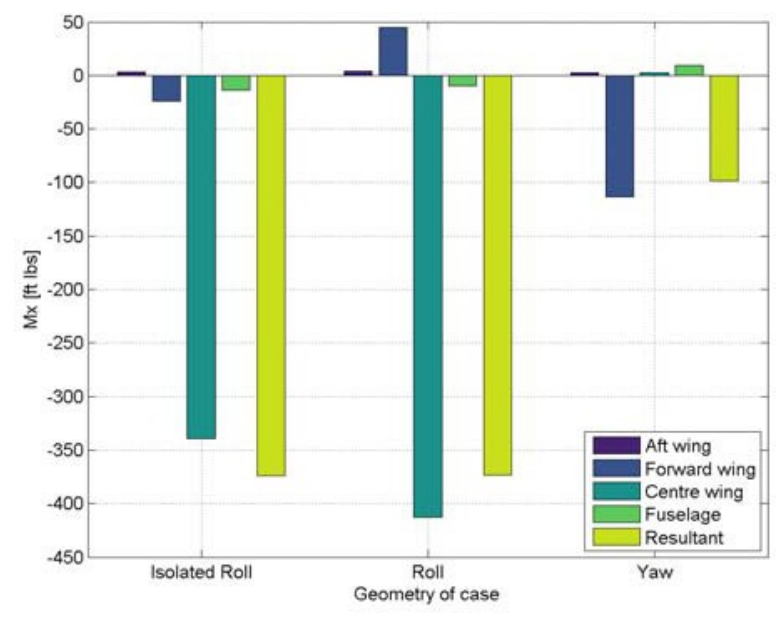

Figure 32: Roll moment in isolated roll compared with raw roll and yaw configurations.

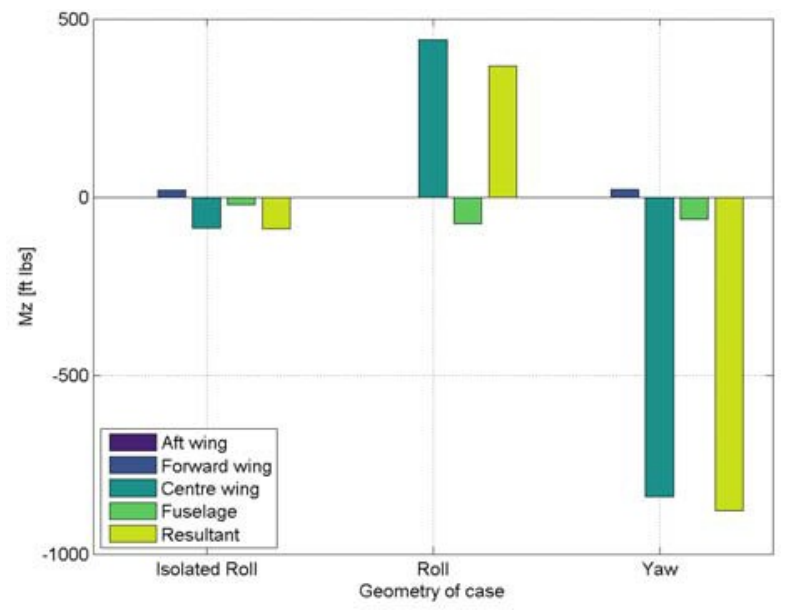

Figure 33: Yaw moment in isolated roll compared with raw roll and yaw configurations.

Here the configuration succeeded in isolating roll, with only a small yaw moment remaining. Further refinement of this control coupling could reduce this remaining yaw response.

\section{NDARC}

The analysis performed has enabled the generation of an NDARC input set describing the Elytron $2 \mathrm{~S}$ experimental aircraft. The aircraft is modeled as a fuselage, two wings and five tails, two rotors, and a propulsion group. The wings represent the forward wing and the center tilt-wing. The tails are modeled to represent the aft wing, vertical wings, and the vertical stabilizer. The rotors are mounted to the center wing and their incidence linked. The louver system is modeled in NDARC as simple force generators when they are deflected to generate roll and yaw moments. The control authority provided by the louvers was taken from the analysis performed in RotCFD. The tail blowing is also represented as a simple force generator to provide pitch control in hover. Table 2 holds the variables extracted and used in the input set for NDARC.

The results from RotCFD including the rotors have not been used for the NDARC input set generation as a wide enough set of conditions suitable for NDARC input have not yet been calculated. The AVL analysis is ideal for this reason; it is faster than RotCFD, allowing more configurations to be included in the analysis. The zero-lift drag estimations made correspond well with the RotCFD results; therefore, the AVL results are adequate for the initial NDARC input set. NDARC includes rotor wake modeling and simplified interaction effects.

With the components defined, their locations are set to represent the Elytron $2 \mathrm{~S}$ configuration. The resulting aircraft geometry is represented by the sketch generated by NDARC found in Figure 34. This is a simple means to check whether or not the geometry is defined correctly. 
Table 2: Variables calculated for NDARC.

\begin{tabular}{|c|c|c|c|c|}
\hline Part & Model & Lift & Drag & Pitching moment \\
\hline Fuselage & Fuselage & $\begin{array}{l}\text { AoA_zero-lift } \\
\text { and AoA_max } \\
\text { together with } \\
\text { lift slope }\end{array}$ & Drag coefficient & $\begin{array}{l}\text { Moment at zero-lift } \\
\text { together with } \\
\text { moment slope }\end{array}$ \\
\hline $\begin{array}{l}\text { Forward } \\
\text { wing }\end{array}$ & Wing & $\begin{array}{l}\text { AoA_zero-lift } \\
\text { and } \bar{C}_{L_{-} \max } \\
\text { together with } \\
\text { lift slope }\end{array}$ & $\begin{array}{l}\text { Drag coefficient } \\
\text { together with } \\
\text { quadratic drag } \\
\text { slope }\end{array}$ & $\begin{array}{l}\text { Moment coefficient } \\
\text { around aerodynamic } \\
\text { center }\end{array}$ \\
\hline $\begin{array}{l}\text { Center } \\
\text { wing }\end{array}$ & Wing & $\begin{array}{l}\text { AoA_zero-lift } \\
\text { and } \bar{C}_{L_{-} \max } \\
\text { together with } \\
\text { lift slope }\end{array}$ & $\begin{array}{l}\text { Drag coefficient } \\
\text { together with } \\
\text { quadratic drag } \\
\text { slope }\end{array}$ & $\begin{array}{l}\text { Moment coefficient } \\
\text { around aerodynamic } \\
\text { center }\end{array}$ \\
\hline Aft wing & Tails & $\begin{array}{l}\text { AoA_zero-lift } \\
\text { and } \bar{C}_{L_{L} \max } \\
\text { together with } \\
\text { lift slope }\end{array}$ & $\begin{array}{l}\text { Drag coefficient } \\
\text { together with } \\
\text { quadratic drag } \\
\text { slope }\end{array}$ & - \\
\hline $\begin{array}{l}\text { Vertical } \\
\text { stabilizer }\end{array}$ & Tail & $\begin{array}{l}\text { AoA_zero-lift } \\
\text { and } \bar{C}_{L_{-} \max } \\
\text { together with } \\
\text { lift slope }\end{array}$ & $\begin{array}{l}\text { Drag coefficient } \\
\text { together with } \\
\text { quadratic drag } \\
\text { slope }\end{array}$ & - \\
\hline $\begin{array}{l}\text { Vertical } \\
\text { wings }\end{array}$ & Tails & $\begin{array}{l}\text { AoA_zero-lift } \\
\text { and } \bar{C}_{L_{-} \max } \\
\text { together with } \\
\text { lift slope }\end{array}$ & $\begin{array}{l}\text { Drag coefficient } \\
\text { together with } \\
\text { quadratic drag } \\
\text { slope }\end{array}$ & - \\
\hline
\end{tabular}

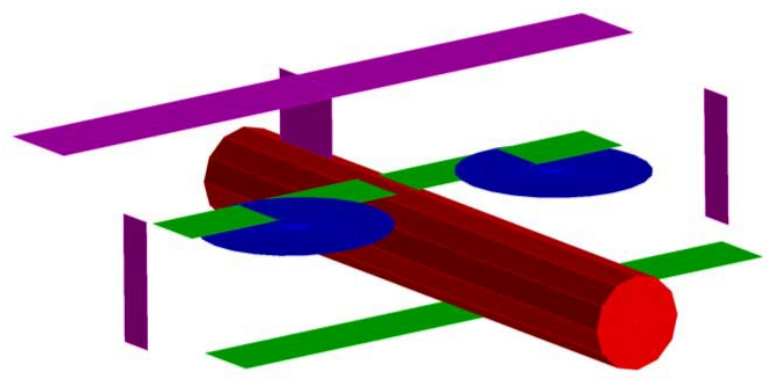

Figure 34. The sketch representation of the Elytron 2S generated by NDARC.

Trim and performance analysis can be performed in NDARC. Furthermore, the flight dynamics (at a conceptual design level) can be modeled with the newly developed tool SIMPLI-FLYD [5]. The flight dynamics analysis in hover and forward flight is described in the next section.

\section{Bare Airframe Flight Dynamics}

A flight dynamics model has been derived from the NDARC model using the SIMPLI-FLYD [5] tool. SIMPLI-FLYD is an integrated collection of software tools that enable a flight dynamics and control assessment from the rotorcraft vehicle design generated with NDARC. It includes a capability to generate linear models at the chosen points of interest. In this process, the NDARC model is run at a range of operating conditions of varying tilt angles and flight speeds to provide the trim state and control input values. The aircraft design and trim data is then passed onto SIMPLI-FLYD where the flight dynamics models are calculated.

\section{Airplane Mode}

At each flight condition point, a linear state space representation of the dynamics is generated by SIMPLI-FLYD in the form:

$$
\mathrm{X}=A \mathrm{X}+B u
$$

Where $\mathrm{x}$ denotes the state and $u$ the input to the system. This provides a model of the local behavior of the aircraft, valid for small perturbation responses. For the analysis of the forward flight airplane mode dynamics, the system is typically decoupled into two parts, one representing the lateral-directional motion and the other representing the longitudinal motion of the aircraft. The values presented here are preliminary values based on the current model of the aircraft.

For the linearized dynamics about a trim condition in airplane mode. The longitudinal dynamics are given by:

\begin{tabular}{|c|c|c|c|c|c|}
\hline $\begin{array}{l}u \\
\mathrm{w}\end{array}$ & $\begin{array}{ll}X_{u} & X_{w} \\
Z_{u} & Z_{w}\end{array}$ & $\begin{array}{l}q-W \\
q+U\end{array}$ & $\begin{array}{l}\text { os } 0_{0} \\
\text { in } 0_{0}\end{array}$ & $\stackrel{u}{\mathrm{w}}$ & $\mathrm{Z}_{8_{\text {coll }}}^{X_{8_{\text {coll }}} \mathrm{X}_{8_{e}}}$ \\
\hline$d t \stackrel{\mathrm{q}}{\mathrm{q}}$ & $\mathrm{M}_{\mathrm{u}} \mathrm{M}_{\mathrm{w}}$ & $\mathrm{M}_{\mathrm{q}}$ & 0 & $\stackrel{q}{e}$ & $M_{\mathrm{o} \text { coll }} \mathrm{M}_{\mathrm{o}_{\mathrm{e}}}$ \\
\hline
\end{tabular}

Where $u$, is the velocity in the body $\mathrm{x}$-axis direction, $\mathrm{w}$ is the velocity in the $\mathrm{z}$ direction, 0 is the pitch angle and $\mathrm{q}$ is the pitching rate. The inputs are collective pitch on the proprotors, $\mathrm{o}_{\text {coll }}$ and the elevator input, $\mathrm{O}_{e}$ driving a pair of elevators on the aft wing. The current implementation on the NDARC Elytron $2 \mathrm{~S}$ does not contain thrust control by varying the prop speed, but it is instead modeled more conventionally by to collectively changing the pitch angle of the rotor blades. For lateral-directional dynamics, the state-space model is given by:

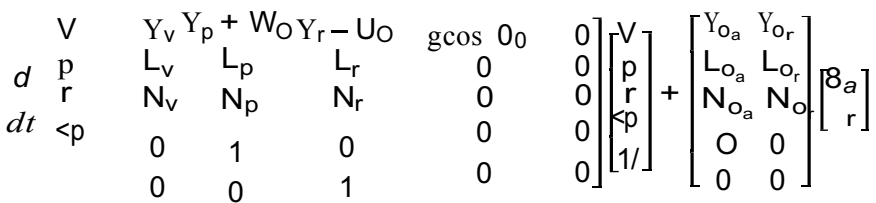

Where $v$ is the velocity in the y direction, $<\mathrm{p}$ and $\mathrm{p}$ are roll angle and roll angular velocity, and $1 /$ and $r$ are yaw angle and yaw angular velocity. The inputs $\mathrm{O}_{a}$ and $\mathrm{o}_{r}$ are aileron and rudder input respectively. Classical linear systems analysis can be performed on the model to obtain the stability of the natural modes of the aircraft. The eigenvalues of the longitudinal and lateral dynamics are plotted in Figure 35Error! Reference source not found. (a) (b).

The longitudinal dynamics exhibit classic behavior for a conventional fixed-wing aircraft, with two oscillatory modes, a low frequency "phugoid" mode and a higher frequency "short period" mode. All the eigenvalues being in the left-half plane of the plot denote that the modes are all stable. The damping ratio of the short period mode is in the range of $\sim 0.39-0.46$ at the aft c.g. location for the range of speeds presented. The effect of moving the c.g. to the forward location increases both the real and imaginary (damping \& frequency) components of the short period mode but actually results in overall reduction damping ratio to $\sim 0.31-0.32$ for the range of speeds presented. Note that at the forward c.g. location the speed range starts at $120 \mathrm{kts}$ rather than $70 \mathrm{kts}$, a consequence of NDARC being unable to find a trim in airplane mode at lower speeds using the elevator only. 
Longitudinal

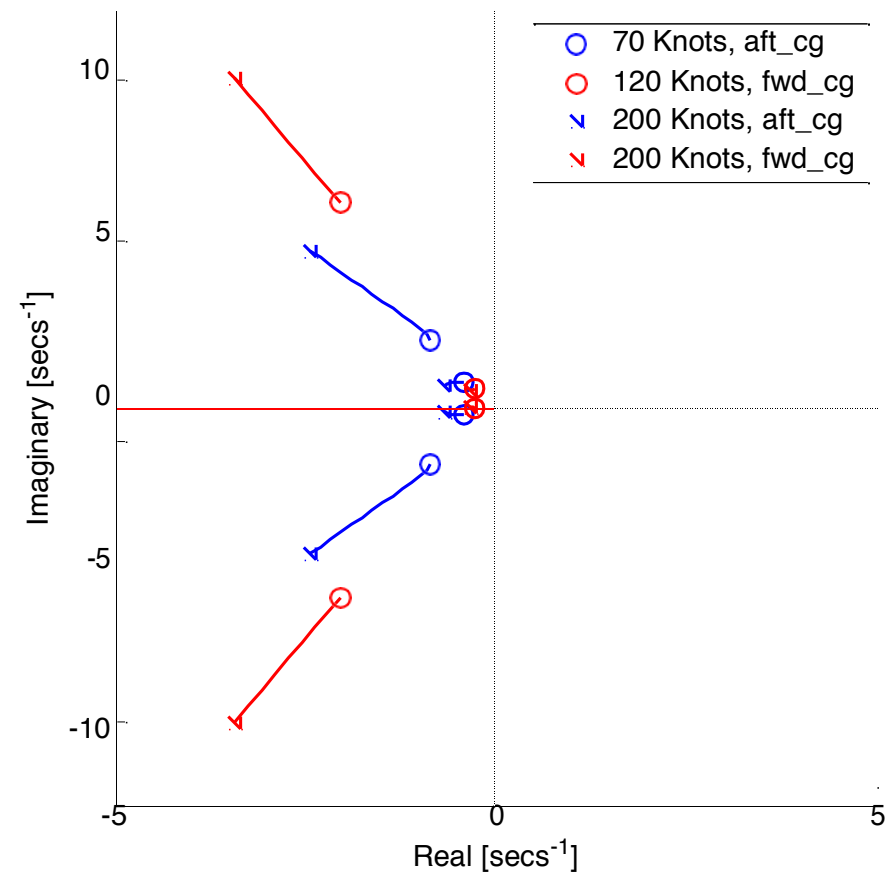

(a)
Lateral



(b)

Figure 35: Longitudinal and Lateral dynamics of the SIMPLI-FLYD Elytron 2S configuration at various speeds in airplane mode.

The lateral-directional dynamics also form the classical set of modes with two aperiodic subsidence modes, the roll and spiral modes, and the oscillatory "dutch roll" mode. The roll mode is on the X-axis that has a large negative real part (between -7 and -18 ) and is only weakly affected by the c.g. change. The spiral mode, which is marginally stable/neutrally stable at the forward c.g. location and unstable for the aft c.g. location, is close to the Y-axis. Both have typical behavior for a fixed wing aircraft; the roll mode essentially has a tendency to damp any rolling motion and the spiral mode is a coupled roll/yaw motion, which, depending on whether it is stable or not, consists of roll/yawing that "spirals" in or out after a disturbance. At the forward c.g. location, the oscillatory dutch roll mode has a frequency of between approximately $3 \mathrm{rad} / \mathrm{s}$ at $120 \mathrm{kts}$ to $5.4 \mathrm{rad} / \mathrm{s}$ at $200 \mathrm{kts}$ with a damping ratio ranging from $\sim 0.29$ to $\sim 0.19$ over the same speed range. At the aft c.g. location and at lower speeds, the dutch roll mode spits into two aperiodic modes that combine into an oscillatory mode at higher speeds. In both c.g. location cases, the dutch roll is relatively weakly damped and is predominately a yaw motion (not shown). This is in part due to the unstable weathercock derivative $\left(N_{V}\right)$ and in part due to the ratios of the roll damping $\left(L_{p}\right)$ to the roll due to yaw $\left(L_{\mathrm{r}}\right)$ derivatives, and the yaw damping $N_{\mathrm{r}}$ to the yaw due to roll derivative $\left(N_{p}\right)$. The large roll damping suppresses the roll motions much more than the yaw damping is able to. However interestingly, the relatively strong negative $L_{\mathrm{r}}$ effect appears to confer overall stability by creating a restoring (negative) roll moment for positive yaw rates despite the unstable $N_{v}$.
The system $(A)$ matrix for lateral-directional dynamics at 120 knots with a forward c.g. location is:

$$
A=\left[\begin{array}{ccccc}
-0.59 & 29.2 & -199.5 & 31.92 & 0 \\
-0.142 & -11.83 & -1.84 & 0 & 0 \\
0.0564 & 1.14 & -0.66 & 0 & 0 \\
0 & 1 & 0.124 & 0 & 0 \\
0 & 0 & 1 & 0 & 0
\end{array}\right]
$$

The system $(A)$ matrix for lateral-directional dynamics at 200 knots with a forward c.g. location is:

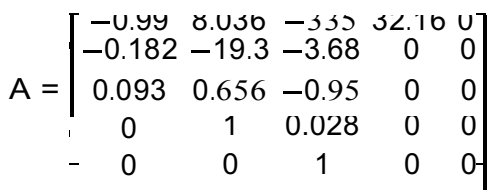

\section{Hover Mode Control}

In hover, the roll and yaw control of the aircraft is intended to be achieved using the center wing louver pair. The effectiveness of the louvers are difficult to predict from empirical datasets so data from RotCFD, a computational fluid dynamics design tool, provided an estimate of the forces and moments that the different louver configurations generate. The section provides a brief evaluation of the stability of the airframe in the hover configuration and evaluates the control power available if the control effectiveness of the louvers is assumed constant for all hover and low speed maneuvering. 


\section{Stability}

First, the open loop modes of the bare airframe are presented in Figure 36. In this case, the coupled longitudinal and lateral dynamics are presented as often the decoupling of rotorcraft dynamics is not always appropriate in the hover. In this figure, the modes have been identified as predominately lateral or longitudinal dynamic responses. The c.g. location is at an intermediate location, half-way between the forward and the aft cases used in the airplane mode calculations as the forward location was unable to trim at hover in the NDARC model used to provide the data to SIMPLI-FLYD.

$$
\mathrm{x}=\left[u, \mathrm{~V}, \mathrm{~W}, \mathrm{p}, \mathrm{q}, \mathrm{r},</, \mathrm{p}, u=\left[\mathrm{o}_{\text {lat }}, \mathrm{o}_{\text {yaw }}\right]\right.
$$

$\left.\begin{array}{cccccccc}-0.11 & -0.002 & -0.012 & -0.031 & 0.05 & 0.014 & 0 & -31.77 \\ 0.0042 & -0.99 & 0 & -0.082 & -0.008 & 0.28 & 31.77 & 0 \\ 0.0245 & 0 & -0.122 & 0 & -0.395 & -0.0002 & 0 & -5.074 \\ 0.001 & -0.0067 & 0 & -0.723 & -0.008 & 0.23 & 0 & 0 \\ 0.01 & 0 & -0.014 & 0.0002 & -0.124 & -0.001 & 0 & 0 \\ -0.001 & 0.061 & 0 & -0.119 & 0.0015 & -0.8 & 0 & 0 \\ 0 & 0 & 0 & 1 & 0 & 0.019 & 0 & 0 \\ 0 & 0 & 0 & 0 & 1 & 0 & 0 & 0 \\ 0 & 0 & 0 & 0 & 0 & 1 & 0 & 0\end{array}\right]$

$$
B=\left[\begin{array}{cc}
0 & 0 \\
0 & 0 \\
0 & 0 \\
0.649 & 0 \\
0 & 0 \\
0 & 0.457 \\
0 & 0 \\
0 & 0
\end{array}\right]
$$

The Elytron 2S exhibits an unstable oscillatory longitudinal mode, most likely the hover phugoid, and a lateral mode with a similar frequency that is marginally unstable. The difference in stability between the two axes being the significantly larger roll damping, $L_{p}$ (see above) conferred by the laterally displaced rotors. All other modes are stable and are aperiodic.

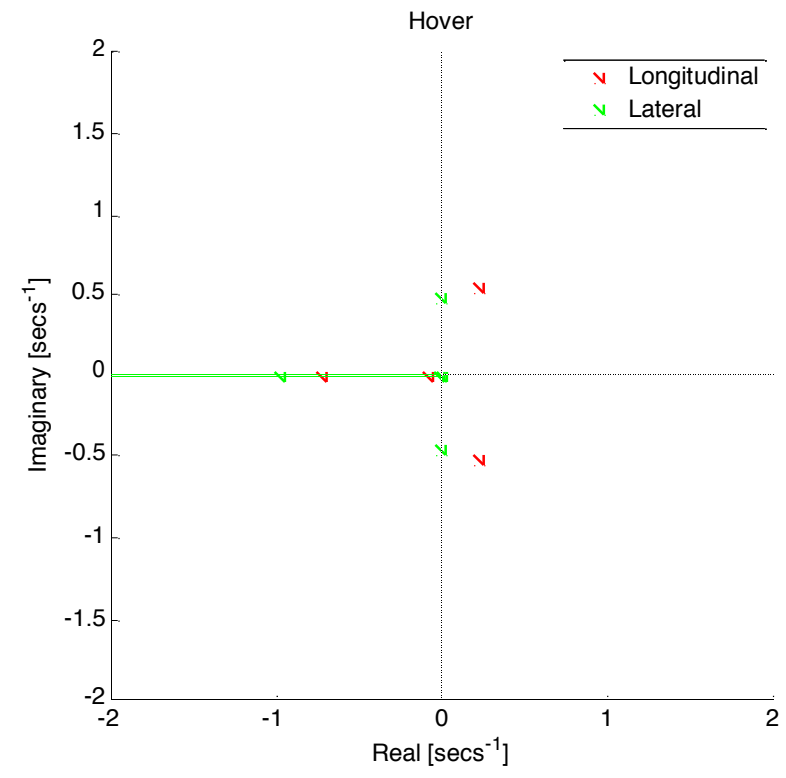

Figure 36: Elytron 2S hover eigenvalues (intermediate c.g.)

\section{Roll and Yaw Control}

As described earlier, the louvers are used to generate rolling and yawing moments in hover. The inertia matrix of Elytron $2 \mathrm{~S}$ is approximately:

$$
I=\left|\begin{array}{ccc}
564 & 0 & 0 \\
0 & 1522 & 0 \\
0 & 0 & 1922
\end{array}\right| \text { slug- } \mathrm{ft}^{2}
$$

The moments generated when the louvers are fully deflected are derived from the RotCFD results described earlier in this paper, and are a maximum roll moment of $M_{\mathbf{x}_{\max }}= \pm 370 \mathrm{ft}$. $\mathrm{lb}$, and a maximum yaw moment of $M_{z_{\max }}= \pm 880 \mathrm{ft}$. lb.

Using this control power, and the inertia matrix above, the theoretical maximum angular velocities are approximately $51 \mathrm{deg} / \mathrm{s}$ for the roll axis and $189 \mathrm{deg} / \mathrm{s}$ for the yaw axis. These calculations are made using the following equations:

$$
\begin{aligned}
& \mathrm{p}_{\text {ss } \max }=-\frac{L_{\mathbf{O}_{\text {lat }}}}{L_{p}} \text { where } L \text { O lat }_{I_{\mathbf{x x}}} \frac{M_{\mathbf{x}_{\max }}}{375} \frac{}{564} \\
& r=-{\frac{N_{\text {yaw }}}{N_{r}}}^{\text {whax }} L_{8_{\text {yaw }}} \quad \frac{M_{z_{\text {max }}}}{l_{z z}} \frac{80}{1922}
\end{aligned}
$$

Using a simplified 1-degree-of-freedom (1-DoF) analysis, where only the control and dynamics in the roll or yaw axis alone are used, the time to reach the peak rates is around 6 seconds for roll, and nearly 30 seconds in yaw. A more informative indicator is the time to reach a particular angular change; for example, again using the $1-\mathrm{DoF}$ model, the time to reach 60 degrees of bank is approx. 2.3 seconds and the time to yaw through 90 degrees of heading is $\sim 2.8 \mathrm{~s}$. 


\section{Conclusions}

This paper presents an initial aerodynamic analysis of the Elytron $2 \mathrm{~S}$ experimental aircraft using low- to mid-fidelity tools aimed to the vehicle conceptual design phase. The aerodynamic analysis was performed with the AVL and RotCFD tools with a focus on low speed forward flight and hover configurations. The results of the aerodynamic analysis were then used to construct an NDARC input set for use in the NDARC and SIMPLI-FLYD tools. The key conclusions from this study are:

- $\quad$ The AVL, RotCFD, NDARC and SIMPLI-FLYD tools were effective in analyzing the complex aerodynamics of this unique vehicle configuration. They provided reliable engineering data in a short time frame allowing for good design practices to be used for the development and refinement of this vehicle.

- $\quad$ For this particular vehicle configuration in low speed loiter conditions, the pitch balance is a complex combination of many factors, including the aerodynamic interactions between the prop wake and the wings, and the c.g. location. The RotCFD and AVL analysis indicated that a c.g. location at least 1.5 feet forward of the center wing tilt point was required to ensure nose down pitching moments, which are key for ensuring pitch stability.

- The forward location of the c.g. in hover results in large nose down pitching moments from the rotors, which would be balanced by the tail blowing system. To produce this nose-up moment, the tail blowing system would need to produce a downward force. A better design choice is to install a lift fan in the nose, which would augment the lift from the rotors and wings, as well as generate the nose-up pitching moment needed to trim the aircraft.

- The flight dynamics analysis performed with the NDARC and SIMPLI-FLYD tools indicate that this vehicle is stable in forward flight, with response modes similar to those of a conventional fixed-wing vehicle of similar size. In hover, the flight dynamics of the $2 \mathrm{~S}$ vehicle are consistent with that of a conventional helicopter. The flight dynamics in the transition region were not analyzed, but a careful analysis of the flight conversion window would be prudent.

\section{References}

[1] Elytron Aircraft Inc., [Online]. Available: http://elytron.aero. [Accessed 2104 2016].

[2] M. Drela and H. Youngren, "AVL," [Online]. Available: http://web.mit.edu/drela/Public/web/avl/. [Accessed 2104 2016].

[3] Sukra Helitek Inc., [Online]. Available: http://sukra- helitek.com/rotcfd.html. [Accessed 2104 2016].

[4] W. Johnson, "NDARC - NASA Design and Analysis of Rotorcraft, Theoretical Basis and Architecture," in American Helicopter Society Aeromechanics Specialists' Conference, San Francisco, CA, January 20-22, 2010.

[5] B. Lawrence, E. L. Tobias, C. Theodore, T. Berger, M. B. Tischler and J. Elmore, "Integrating Flight Dynamics \& Control Analysis and Simulation in Rotorcraft Conceptual Design," in to be presented at AHS 72nd Annual Forum, West Palm Beach, FL, May 17-19, 2016.

[6] W. Koning, C. Acree and R. Rajagopalan, "XV-15 Tilt Rotor Performance Validation Using Computational Fluid Dynamics," in AHS Technical Meeting on Aeromechanics Design for Vertical Lift, San Francisco, 2016.

[7] K. Guntupalli, L. Novak and R. Rajagopalan, "RotCFD: An Intergrated Design Environment for Rotorcraft," in $A H S$ Specialists' Conference on Aeromechanics Design for Vertical Lift, San Francisco, 2016.

[8] R. Rajagopalan, V. Baskaran, A. Hollingsworth, A. G. Lestari, E. Solis and B. Hagerty, "ROTCFD - A Tool for Aerodynamic Interference of Rotors: Validation and Capabilities," in $A H S$ Futur Vertical Lift Aircraft Design Conference, San Francisco, 2012.

[9] N. Barbely, N. Komerath and L. Novak, "A study of Coaxial Rotor Performance and Flow Field Characteristics," in $A H S$ Technical Meeting on Aeromechanics Design for Vertical Lift, San Francisco, 2016.

[10] S. Sahin, C. Russell, E. Solis and R. Rajagopalan, "Analysis of Large Civil Tilt Rotor Wind Tunnel Blockage and Validation Using RotCFD," in AHS International technical Meeting on Aeromechanics Design for Vertical Lift, San Francisco, 2016.

[11] W. Johnson, "NDARC NASA Design and Analysis of Rotorcraft," NASA, 2015.

[12] W. Johnson, "NDARC NASADesign and Analysis of Rotorcraft Theory Appendix 7," NASA, 2012.

[13] "OpenVSP," [Online]. Available: http://www.openvsp.org/. [Accessed 2104 2016].

[14] M. Drela and H. Youngren, "XFOIL," [Online]. Available: http://web.mit.edu/drela/Public/web/xfoil/. [Accessed 2104 2016].

[15] S. F. Hoerner, Fluid-dynamic Drag, Published by the Author, 1965.

Page 14 of 15 


\section{Acknowledgments}

Eduardo Solis at NASA Ames Aeromechanics department deserves acknowledgment and thanks for his time in providing the edited model of the 2S CAD for analysis in RotCFD.

Adam Ewert, an intern at NASA Ames Aeromechanics department, has also spent time modeling different configurations of the aircraft together with creating a deflectable louver model. On top of this he has also assisted in the RotCFD analysis.

Carl Russell assisted in getting started in AVL.

Dr. Wayne Johnson for his assistance in debugging the NDARC database.

Dr. William Warmbrodt for his guidance with the XV-15 rotor.

\section{Definitions/Abbreviations}

$\operatorname{AoA}$

Angle of Attack

AVL

$\mathrm{C}_{\mathrm{D}}$

C $_{\text {Do }}$

$\mathrm{C}_{\mathrm{L}}$

$\mathrm{C}_{\text {Lmax }}$
Athena Vortex Lattice

Zero-lift drag coefficient

Drag coefficient

Lift coefficient

Maximum lift coefficient
Drag

$\mathbf{L}$

$\mathbf{F}_{\mathbf{x}}$

$\mathbf{F}_{\mathbf{z}}$

$\mathbf{M}_{\mathbf{x}}$

$\mathbf{M}_{\mathbf{y}}$

$\mathbf{M}_{\mathbf{z}}$

NDARC

Lift

$\mathbf{R}$

RPM

Force in $\mathrm{x}$-axis(Drag)

Force in $\mathrm{z}$-axis(Lift)

Moment about x-axis(Roll)

Moment about y-axis(Pitch)

Moment about z-axis(Yaw)

NASA Design and Analysis of Rotorcraft

Radius

Revolutions per minute

V

VTOL

Velocity

Vertical Take Off and Landing

p

Density 